\title{
The Marmaray Project in Istanbul: a shift from roads to railways
}

\author{
A. U. Oktem \\ Istanbul Bilgi University, Department of Economics, Turkey
}

\begin{abstract}
Istanbul is one of the biggest metropolitans in the world with over ten million inhabitants. Increasing population and disposable income have led to an increase in the demand for transportation in daily life. Unfortunately, the demand for transport is met mostly by the increasing use of cars. As a result of that, environmental problems associated with the use of cars raise concerns. In order to tackle both urban traffic congestion and air pollution, local authorities and the government are investing in alternative modes for urban transportation to road transport modes. Of these, the most notable one is the Marmaray Project. In fact, this project is also one of the most interesting transport projects of the world. The aim of the project is to shift the demand from road transportation on the bridges over the Istanbul Straight to public transportation with rail systems. The project consists of five parts: a rail system from Gebze to Sogutlucesme, a bored tube system under the surface between Sogutlucesme and Uskudar on the Asian side of Istanbul, an immersed tunnel under the Istanbul Straight from Uskudar to Sirkeci, a bored tunnel under the surface between Sirkeci and Kazlicesme and again a rail system from Kazlicesme to Halkali on the European side of Istanbul. The objectives of the Marmaray Projects are various. It has been estimated that when the project has been completed, the number of passengers travelling by the rail system will dramatically increase and Istanbul will have an efficient urban public transport system, which will significantly contribute to policies taken to cope with urban traffic congestion and air pollution caused by traffic.

Keywords: immersed tube tunnel, bored tube tunnel, the Marmaray Project, urban traffic, congestion, air pollution.
\end{abstract}




\section{Introduction}

Traffic congestion, air pollution and noise associated with road transportation, in particular, with the use of private cars are some of the major nuisances metropolitans suffer from. Since transportation is an essential component of daily life, the aim of policy makers should be to encourage commuters to use more environmentally friendly modes rather than to restrict their mobility. Efficient public transportation can be considered as a more environmentally mode since fuel consumption per passenger is much lower than a car. More importantly, it will significantly contribute to reducing congestion in urban areas. There are several ways of shifting the demand for transportation from private cars to public transport. Efficient, punctual, comfortable and reliable public transport system will be able to get commuters out of their car. Istanbul is one of the cities where traffic congestion is a main problem, which calls for an urgent solution. The Marmaray Project, an immersed tube tunnel linking Asia with Europe under the Istanbul Straight, is the most important investment aiming at coping with traffic congestion. The aim of this study is to examine the impact of the Marmaray Project on the daily traffic of Istanbul. The following section concentrates on the question of why congestion is a problem and on road pricing implemented in various cities to tackle congestion. Section three is devoted to the general view of the traffic of Istanbul. Section four discusses how the Marmaray Project will contribute to reducing the traffic congestion in Istanbul. Section five is a concluding one.

\section{Traffic congestion and road pricing}

Traffic congestion continues to be a severe problem in urban areas. The main reason for congestion is the excessive demand for a limited supply of road space. Congestion causes decreased mobility and inefficient use of time. There are some environmental problems associated with congestion such as increased pollution and noise. All these problems are regarded as transport externalities. It was Arthur Pigou [1], who pointed out the problem of externality and the need for government intervention to solve the problem in question. Pigou suggested that taxes, known as Pigouvian taxes in the literature, can be used as a tool of government intervention in correcting externalities. Since then, Pigouvian taxes as a solution to the problem of externality have attracted a great deal of attention from various bodies. The use of Pigouvian taxes is very common and their implementation can be seen in various kinds in a number of countries (EEA [2]; OECD [3]). As in the case of other externalities, fiscal incentives can be enacted to make road users bear the full cost of their travel rather than only private costs of running a car such as fuel taxes and annual license fee. According to CEC [4], one of the ways of doing so is road pricing, which is becoming a popular policy due to its effectiveness. It can be applied on a local basis where congestion is experienced and it can be differentiated according to the time of a day. On the other hand, there may be some problems such as technical, administrative and political problems associated with putting road pricing into force (see 
Morrison [5]). However, there are some experiences, which indicate that road pricing can be implemented successfully despite the opposition coming from commuters. Among those, there are three examples, which deserve closer attention.

\subsection{Area License Scheme}

The Area License Scheme (ALS) is the first road pricing implemented in the world to cope with congestion. The ALS was introduced in Singapore. The Singapore government took some actions to combat congestion, including the ALS (see Smith [6]; Phang and Toh [7]). By introducing such a system, the operating cost of vehicles in a defined area, which was the most congested area and called as the restricted area, was increased. The idea was that vehicles entering the restricted area during the morning peak hours, from $7.30 \mathrm{a} . \mathrm{m}$. to 10.15 a.m., were supposed to purchase a ticket and display it before entering the restricted area. Sunday and public holidays were exempted from the ALS (McCarty and Tay [8]). The license fee was not standard and differentiated according to the type of vehicles and there were some exemptions such as buses, good vehicles and car pools carrying at least four people. Furthermore, in order to contribute to the success of the ALS, parking charges in the restricted area were increased substantially (Armstrong-Wright [9]). Finally, cheaper parking places outside the restricted area were provided with public transportation to the restricted area. The outcomes of the ALS were promising. The share of work journeys by bus in total increased from 33 per cent to 69 per cent between 1975 and 1983. Car pools increased from 23 per cent to 47 per cent over the same period. A dramatic fall in traffic volume from 71.2 per cent to 63.3 per cent was experienced by May 1983 (Morrison [5]). As of 1 June 1989, all types of vehicles were made subject to the fee. Just ambulances, fire brigades, public buses and military vehicles were exempted from the fee. Moreover, the implication of the ALS was extended to include the evening peak hours from 4.30 p.m. to 6.30 p.m. Since the number of cars entering the restricted area before and after the restricted hours increased, the government announced the introduction of the Road Pricing System (RPS), which can be applied for 24 hours a day. The implementation of the RPS is similar to the RPS tested in Hong Kong. The impacts of the PRS on traffic volume at peak hours are outstanding. It was reported that road traffic was decreased by almost 25,000 vehicles at peak hours, resulting in a fall by 13 per cent in traffic in the restricted area (hhtp://en.wikipedia.org). Moreover, as in the case of the ALS, car-pooling increased and all these developments resulted in a more efficient use of existing roads.

\subsection{Electronic Road Pricing}

Hong Kong was the first country to test the technical feasibility and realibity of the Electronic Road Pricing (ERP). A pilot area was chosen for this purpose and testing period lasted for 21 months. Electronic number plate (ENP) was installed over 2,500 vehicles. The number of government vehicles was about 1,200 and 
buses accounted for about 700 and the rest belonged to volunteers commuting in the pilot area (Armstrong-Wright [9]). The plan was to install an ENP in vehicles. Electronic loops buried under the road surface at each charging point. As the vehicle passed each charging points, the ENP transmitted its number to electronic loops, which stored the information. The stored information included the time at which the vehicle passed and the place from which the vehicle passed. Fees were arranged depending on location and time. Finally, calculated fees were sent vehicle owners at the end of each month. Results derived from testing the system indicated that the system is accurate and sufficently reliable to be extended (Catling and Dawson [10]). Hau [11] also shows the impact of the ERP on the traffic and different modes such as private cars, taxis and public transport. Unfortunately, after the trial in question, the introduction of the ERP did not come true permanently for different reasons.

\subsection{London Congestion Charge Scheme}

In order to tackle congestion heavily experienced in the centre of London, a congestion charging scheme (CCS) was introduced by London Mayor in 2003. It should be noted that the London Congestion Charge Scheme (LCCS) is the first example of its kind implemented in a major European city. It is planned that revenues raised from the LCCS will be invested in transport projects of London. This is an important decision since it will minimise the opposition coming from negatively affected groups and financially contribute to the improvement of public transportation. The LCCS covers only weekdays, from Monday to Friday between 7.00 a.m. and 6.30 p.m. Private car drivers are subject to the LCCS, which is currently 8 pounds. Residents living in the defined area receive a 90 per cent discount. There are some exemptions from the LCCS. Buses, licensed taxis and mini-cabs are among the exempted vehicles. It can be said that the purpose of the exemption is to make a shift from private cars to public transportation (www.vtpi.org). When taking into account the fact that certain alternatively fuelled vehicles and bicycles are also exempted from the LCCS, it can be realised that the CCS also aims at reducing air pollution caused by the use of vehicles in the defined area. Since the introduction of the LCCS, there has been a fall in traffic by 18 per cent at the operational hours of the CCS. The number of commuters travelling by buses has increased by 29,000 during the morning peak hours (www.citymayors.com).

\section{A general view on Istanbul traffic}

Istanbul is the biggest city in Turkey and also the heart of Turkey with financial institutions, industrial and cultural activities. The most important feature of Istanbul is its unique geographical position. Istanbul links Asia and Europe through two bridges, the Bosphorus and Fatih Sultan Mehmet, over the Istanbul Straight. Therefore, it plays an important role in transportation activities between the continents. Unfortunately, the people of Istanbul suffer from heavy congestion. Congestion occurs due to the dominance of road transport modes in 
daily traffic. If no measures are taken to shift the demand from road transportation to alternative modes, congestion problem will get even worse as a result of the increasing demand for transport. Policy makers are aware that congestion level has already reached an unacceptable level and that the shift from road transportation to alternative modes is inevitable to tackle congestion in the long run. To tackle congestion, authorities must provide cheap, reliable, comfortable, punctual and efficient public transportation for the people of Istanbul. To do that, a tremendous amount of investment in transportation is required and Istanbul Metropolitan Municipality has planned to spend 60 per cent of its 2006 budget on transportation investment as the starting point.

The people of Istanbul, unfortunately, have to travel mostly by road transportation due to inadequate alternative modes. The need for transportation is met by 16 different modes in Istanbul. Road modes dominate the need for transportation by accounting for 90 per cent of total traffic, of which the share of private cars is 31.94 per cent. According to the data provided by the State Planning Office (SPO), Istanbul is a city where the number of vehicles registered is the highest in Turkey. There were 2,224,793 registered cars in 2005 and the number of cars in use increases by around 200-250 cars each day (www.die.gov.tr). Depending on economic growth it can be said that the number of cars per person will continue to increase and this will worsen the current situation. Mini-buses follow the use of cars, accounting for 22.18 per cent. The share of public buses including buses operated by private sector is 15.52 per cent. The first bus was run in 1926 for road public transportation. Before that, tram-cars run by horses were used for public road transportation. Depending on the shift from railway to road transportation for passenger transport and the increasing number of commuters in daily traffic the number of buses used for daily traffic in the city increased to 2,580 in 2001 . In addition, the number of buses operated by private companies for daily traffic is 1,318. There are 140 lines for mini-buses and the number of mini-buses is 6,500. The length of road network is $3,600 \mathrm{~km}$ under the responsibility of Istanbul Metropolitan Municipality. Although Istanbul is surrounded by the Marmara Sea, the Black Sea and the Istanbul Straight, the share of sea transportation is only 3 per cent in total transportation. Railway system constitutes 6-7 per cent of total traffic (www.ibb.gov.tr). As a result, it can be said that the use of private cars is very common for daily traffic and this causes heavy congestion especially on the bridges over the Istanbul Straight in the morning and evening hours.

When compared Istanbul with other major European cities, it can be easily seen that alternative modes such as sea transportation and railway system have been neglected for many years. The shift from road transportation to other alternatives modes is a priority issue in the European Union (EU) to achieve sustainable transport. The White Paper by the European Community [12] proposes around 60 measures to balance unequal development transport modes. The concept of combined transport known also as the PACT program (19972001) developed also by the EU emphasises the importance of alternative transport modes to road transportation in term of sustainable transport. The aim of the program is to encourage Member States to invest in revitalising the 
railways and promoting transport by sea and inland waterway. The EU announced that it will help to finance the infrastructure of these kinds of projects in the case of the shortage of financial sources. Moreover, if a Member State undertakes a joint project with a non-member neighbouring state, both member and non-member states will receive financial aid from the EU funds. The PACT programme ended on 31 December, 2001 and was replaced by the MARCO POLO programme, which follows the objectives of the PACT programme.

Istanbul Metropolitan Municipality is also aware of the importance of alternative modes in reducing congestion to road transport modes. The priority of Istanbul Metropolitan Municipality is to increase the share of rail systems in total traffic. The Marmaray Project, as will be dissussed in Section 4, will be the most interesting component of railway systems in Istanbul. Travelling by the underground in Istanbul is a fairly new concept. Actually, Istanbul in Turkey is the only city where an underground system exists. The construction of the underground was started in 1992 and completed in 2000. As can be seen from Table 1, the length of the underground is rather short. It has only two lines and six stations. It is punctual and departure interval is just 5 minutes. Passenger capacity 70,000 people/hour-one way. The increase in the number of commuters travelling by the underground shows that the people of Istanbul long for travelling by comfortable public transportation. For instance, the number of commuters travelling by the underground was 3 million 359 in January 2005 and increased to 4 million 720 in December 2005. This means that a rise of 40 per cent in the number of commuters travelling by the underground was seen just in a year.

Table 1: $\quad$ Existing Metro systems in Istanbul.

\begin{tabular}{|l|c|c|}
\hline & $\begin{array}{l}\text { Taksim-4 Levent } \\
\text { Underground }\end{array}$ & $\begin{array}{l}\text { Aksaray-Airport } \\
\text { Light Rail }\end{array}$ \\
\hline Length of line & $8 \mathrm{~km}$ & $20 \mathrm{~km}$ \\
\hline Number of stations & 6 & 18 \\
\hline Departure interval & 5 minutes & $5-7,5-10,15$ minutes \\
\hline Speed & $40 \mathrm{~km} / \mathrm{h}$ & 31 minutes \\
\hline Journey duration & 11 minutes 30 seconds & 165 thousand \\
\hline Number of passenger a day & 140 thousand & \\
\hline
\end{tabular}

Source: www.ibb.gov.tr

As can be seen from Table 1, the other important railway system under the responsibility of Istanbul Metropolitan Municipality is Aksaray-Airport Light Rail System, which started to operate in 1989. Later, current extensions were made. The duration of the journey between the first and last station is 31 minutes and passenger capacity is 24,000 people/hour-one way. In addition to the underground system and light rail, there is a tram-line between Eminonu and Zeytinburnu. The length of the line is $11.2 \mathrm{~km}$ with 20 stations. Departure interval is 2.5 minutes and the duration of the journey between the first and last station is 40 minutes. Passenger capacity is 12,000 people/hour-one way. The difference between the tram-line and the other railways systems mentioned above is that the former runs through within road traffic. 


\section{Immersed tunnels and the Marmaray Project}

The idea of constructing immersed tunnels is not new and the history of immersed tunnels goes back to 1906. Michigan Central Railroad Tunnel in the USA constructed between 1906-1910 was the first type of its kind. Since then, immersed tunnels have been constructed for traffic purposes in various countries. For instance, the Netherlands was the first country in Europe to construct an immersed tunnel, the Mass Tunnel in 1942. Japan constructed Aji River Tunnel in Osaka in 1944. As the technique of immersed tunnel for construction has improved, the number of immersed tunnels has risen significantly. Immersed tunnels can be considered as an alternative to bridges. There are some examples of immersed tunnels in various countries of the world. Some of these immersed tunnels are already operational, whilst others are under construction. Immersed tunnels are mostly seen in the USA, the Netherlands and Japan.

The first immersed tunnel will be the Marmaray Project in Istanbul, which is being constructed. Istanbul Metropolitan Municipality is planning to finish the project in Autumn 2009 and a trial operation will be made in Autumn-Spring 2009/2010 and the Marmaray will be in operation in Spring 2010. The objectives of the Marmaray Project are various. Of those, reducing congestion and related environmental problems will play an important role to achieve sustainable transportation. When completed, the project will offer an alternative transport mode, railway system, to the existing road transportation. Since travelling time from and to the European side of Istanbul will dramatically fall, it is expected that the Marmaray Immersed Tunnel will attract many commuters travelling between the both sides of Istanbul. Depending on the decreasing congestion level in urban traffic, some environmental benefits will be realised: reduced energy consumption for transportation, as a result of that reduced air pollution, reduced noise pollution coming from braking and accelerating in heavy traffic. Since the railway system on the European side will be mostly in historical places of Istanbul, historical buildings and places will also be protected from air pollution caused by traffic congestion.

Turkey is receiving funds for financing the project from various bodies. An agreement between Turkey and the Japanese Bank for International Cooperation (JBIC) was signed. The loan provided by the JBIC covers the cost of the Istanbul Straight Crossing portion of the project. This portion is equal to 35 per cent of the entire cost of the project. The amount of the loan provided by the JBIC is 1 billion and 60 million US dollar. The other funding body is the European Investment Bank (EIB). In addition to 400 million Euro loan signed earlier, Turkey will receive 650 million Euro from the EIB. This loan is the largest amount provided by the EIB to a project in Turkey. It is also worth noting that, to be eligible to receive financial support from the EIB for transport projects, transport projects are required to be sustainable. The remaining costs of the project will be met either by international financing institutions and or by private funding through the government. 


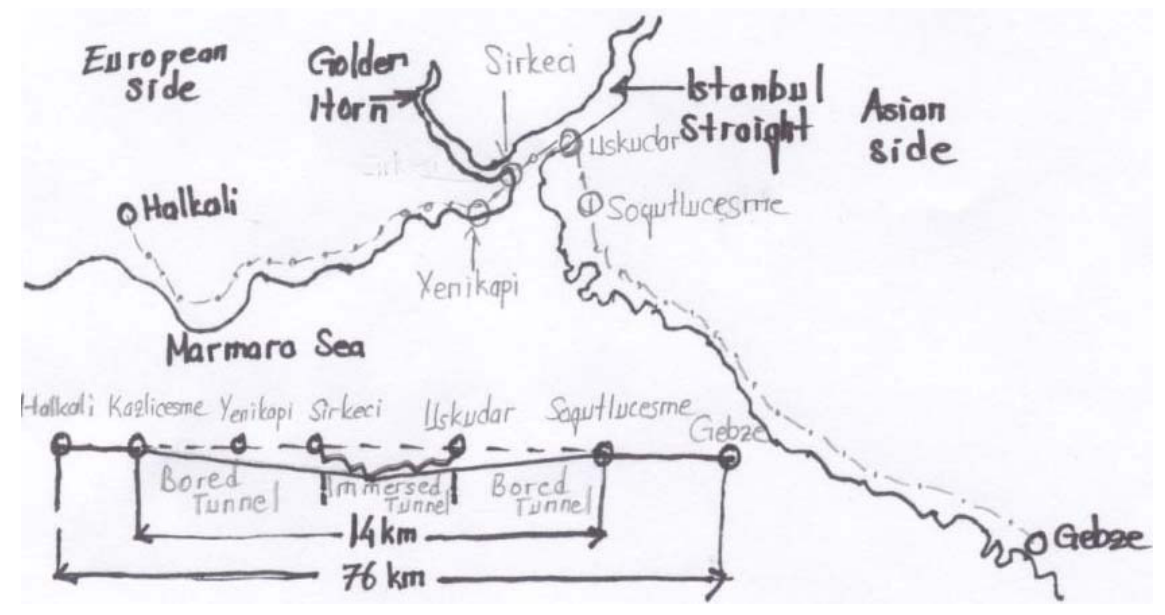

Figure 1: $\quad$ Marmaray Project.

Figure 1 illustrates the Marmaray Project linking Asia with Europe through a commuter rail system. The rail system consists of five parts: On the Asian side the existing railway system between Gebze and Sogutlucesme will be revitalised. A bored tunnel will be constructed between Sogutlucesme and Uskudar and it will continue under the Istanbul Straight as an immersed tunnel until Sirkeci. On the European side a bored tunnel between Sirkeci and Kazlicesme will be constructed and between Kazlicesme and Halkali the existing railway system will be revitalised. The entire revitalised and new railway systems including the immersed tunnel will be $76 \mathrm{~km}$ at length. There will be 3 new underground stations in Yenikapi, Sirkeci and Uskudar and 37 surface stations on the existing railway lines between Gebze and Halkali. One of the most challenging features of the Marmaray Project is that the immersed tunnel, which will be constructed beneath the Istanbul Straight, is the deepest of its kind with $58 \mathrm{~m}$ under the water surface.

A journey between Halkali and Gebze before the operation of the project takes more than three hours, including the sea journey on the Istanbul Straight. When the Marmaray Project starts to operate, the journey between Halkali and Gebze will take one hour and forty-five minutes. If the total number of commuters is taken into consideration, this will lead to a tremendous amount of time saving. For instance, it has been estimated that the total time saving will be around 13 million hours in 2009. The time saving, of course, will increase depending on the increase in the number of commuters travelling by the Marmaray. Through a transport model, Istanbul Technical University forecasted passenger demand by using data in 2002 and 2003. The results derived from the model are promising. According to the results, the number of commuters travelling by the Marmaray will be approximately 1,500,000 per day in 2015 (www.marmaray.com). 
Table 2: $\quad$ Properties of the Marmaray Project.

\begin{tabular}{|l|c|}
\hline Existing rail system & 10,000 commuters per hour \\
\hline Marmaray & 70,000 commuters per hour \\
\hline Design speed & $100 \mathrm{~km} /$ hour \\
\hline Maximum operational speed & $100 \mathrm{~km} / \mathrm{hour}$ \\
\hline Expected mean speed & $45 \mathrm{~km} / \mathrm{hour}$ \\
\hline Duration of interval & $2-10$ minutes \\
\hline Number of stations & 37 \\
\hline Number of underground stations & $76 \mathrm{~km}$ \\
\hline $\begin{array}{l}\text { Length of the Marmaray including } \\
\text { revitalised rail system }\end{array}$ & \\
\hline
\end{tabular}

Source: www.marmaray.com

In addition to the Marmaray Project, there are other railway projects of Istanbul Metropolitan Municipality. When these projects have been completed, the Marmaray will play a key role in connecting the railway systems on the both sides of Istanbul. The underground will be extended to Ayazaga in the north and to Yenikapi in the west on the European side. The underground will be connected to the Marmaray at Yenikapi station. The Aksaray-Airport Light Rail System will also be connected to the Marmaray at Yenikapi station. On the Asian side of Istanbul a light rail system will be also constructed from Kadikoy to Kartal and there will be a connection between the light rail system and the Marmaray at Ibrahimaga Station. When all these projects have been completed and connected to each other, Istanbul will have a modern and efficient railway system offering a comfortable and uninterrupted journey to the people of Istanbul. When compared the share of the railway systems in Istanbul with those in other metropalitans in the world, it can be said that Turkey is far from having sustainable transport policy. The share of the railway system in total transportation in New York is 40 per cent, while the railway system accounts for 35 per cent of total transportation in Paris. The share of the railway systems in daily traffic was 3 per cent in 1997 in Istanbul. When Taksim-4 Levent started to operate in 2000 and Aksaray-Airport Light Rail extended, the share of the railway system in total increased to 6-7 per cent in 2005. When the Marmaray Project has been completed, it is expected that the share of the railway systems will increase to 27.7 per cent in 2010 (www.ibb.gov.tr). The integration of seaways and railways will play an important role in coping with congestion and reaching the optimum use of public transportation. In order to encourage commuters to travel by the Marmaray, Istanbul Metropolitan Municipality can introduce a road pricing system similar to those explained in Section 2. Fortunately, Istanbul Metropolitan Municipality is planning to introduce such as system. Experts also suggest that private car users can park their car in parking areas provided very close to the railway system and they can continue their journey by public transportation. This kind of policy was already implemented in Singapore to encourage private car users to travel by public transportation. 


\section{Conclusion}

The people of Istanbul suffer from the problem of congestion and the increasing use of cars due to inadequate public transportation is worsening the current situation. Therefore, Istanbul Metropolitan Municipality has planned to invest in transport projects, which will offer comfortable and uninterrupted journeys to the people of Istanbul. Of these projects, the Marmaray Project is the most impressive one. The Marmaray will link Asia with Europe under the Istanbul Straight through the immersed tunnel. When the Marmaray starts to operate, it is expected that there will be a shift from road transportation to railway system. As a result of this, there will be some environmental benefits such as reduced energy consumption, reduced air and noise pollution. Moreover, since Istanbul is a historic city, historical buildings will be also protected from air pollution caused by the traffic.

\section{References}

[1] Pigou, A. "The Economics of Welfare", First Edition, London, Macmillan, 1920.

[2] EEA, "Environmental Taxes: Recent Developments in Tools for Integration", Copenhagen, 2000.

[3] OECD, "Evaluating Economic Instruments for Environmental Policy", Paris, 1997.

[4] CEC, COM(92), "Green Paper on the Impact of Transport on the Environment", Brussels, 1992.

[5] Morrison, S. A. "A Survey of Road Pricing", Transportation Research A, 20A, 129-134, 1986.

[6] Smith, P. "Controlling Traffic Congestion by Regulating Car Owners", Journal of Transport Economics and Policy, 16, 89-95, 1992.

[7] Phang, S. and Toh, R. S. "Curbing Urban Traffic Congestion in Singapore: A Comprehensive Review", Transportation Journal, 37, 24-33, 1997.

[8] McCarty, P. S. and Tay, R. "Road Pricing Congestion: Recent Evidence from Singapore", Policy Studies Journal, 21, 296-308, 1993.

[9] Armstrong-Wright, A. T. "Road Pricing and User Restraint: Opportunities and Constraints in Developing Countries", Transportation Research A, 20A, 123-127, 1986.

[10] Catling, I. and Dawson, J. A. L. "Electronic Road Pricing in Hong Kong", Transportation Research, 20A, 129-134, 1986.

[11] Hau, T. D. "Electronic Road Pricing: Developments in Hong Kong 19831989", Journal of Transport Economics and Policy, 24, 204-214, 1990.

[12] European Community, "White Paper European Transport Policy for 2010: Time to Decide", Luxembourg, 2000. 